\title{
INVESTIGATION OF VARIATIONS IN THE SOFTWARE DEVELOPMENT PROCESS: A CASE STUDY
}

\author{
Yılmaz GÖKŞEN, Dokuz Eylul University, Faculty of Economics and \\ Administrative Sciences, yilmaz.goksen@deu.edu.tr \\ Sabri ERDEM, Dokuz Eylul University, Faculty of Business, \\ sabri.erdem@deu.edu.tr \\ Bilgehan ÖZTÜRK, NTX Company, İzmir, bilgehan.ozturk@NTX.com.tr
}

\begin{abstract}
This study employs the business software project variations in understanding the customer. The relevant literature shows many business software implementation failures and their reasons. Our research is based on a real case study in Turkey and it has a potential for encountering in any location of the world as well as in Turkey. We focus on a business software implementation process and obtain observational data from project meetings and interviews. Our findings show that the most of the factors, that affect the software development process' success; are understanding the customer, good communication and promises.
\end{abstract}

Keywords: Software development process, software project management, software project failures

\section{INTRODUCTION}

Business environment has radically changed during the transformation of information technology and management. Advancing technologies have encouraged a migration away from the traditional, life cycle methods of development toward more flexible and dynamic approaches in which reusable components are assembled into working systems in a radically shorter time (Welke, 1994).

Today, there are few technical reasons for companies to experience the software project management as compared to 20 years ago. Most of the risks in 
today's system development process are due to management and organization rather than technological infrastructure. Information systems projects continue to fail at an alarming rate, and the problem of 'runaway' development projects has never been more serious (Lyytinen and Robey, 1999).

Contents of agreements on implementing software between software developers and companies are subject to variation during the new product development and/or process improvement in terms of time requirement, cost of implementation, product specifications and allocated resources that depends highly on other factors such as application area, specific needs when implementing standard software, user knowledge level and top managers' point of view. These variations may cause unplanned negative situations for both software developers and companies as customers.

Business software like Enterprise resource planning (ERP) automates core corporate activities such as manufacturing, human resource, finance and supply chain management by adapting and incorporating 'best practice' that facilitates rapid decision-making, cost reductions and greater managerial control. However, there is extensive evidence of IT implementation project failure in the academic and business literature. Many surveys showed that large portion of software projects fail completely, that is, the system is not delivered or is unusable (Holland and Light, 1999).

According to the existing literature related to the software development, several models have been structured for standard software development processes. These include the waterfall model, spiral model and evolutionary models that can be regarded as favorites. Software development supported by Computer Aided Software Engineering (CASE) tools, especially Joint Application Development (JAD) and Rapid Application Development (RAD) among these tools, and the 5th Generation Software Development tools (i.e., model-based software development), can be considered as modern approaches. Although software development models reach a certain maturity and structure, in practice, applying these models do not seem very possible especially for concerning project-based software needs.

The main reasons for these impossibilities are thought to include factors such as rashness of the firm that needs to use the software, the level of trust in scientific management, customers' lack of knowledge on cost items and their insufficient information of the project about the implementation process. However, it is necessary to investigate the effects of the product structure, application area, company ownership structure, software development techniques that the software developer is capable to use professionally on the software implementation process triggered by the agreement.

In this study, it is aimed to investigate the main and secondary sources of variations in understanding of needs, and try to minimize the time, allocated resources, product specifications and costs related deviations that are highly possible to emerge during the project development. 
This study utilizes information about the software developer company and Ozlnc, structured observations, interviews, analysis forms, the initial commitments, pre and post analysis results of the project needs, project maps, meeting notes and conversations as a primary data source. The software company here is a leading business solution provider with standard enterprise ERP software and customizable products and OzInc is growing rapidly in semi product steel sector.

The customer company that is subject to our case study achieves both countrywide and international trade facilities in other countries. These collected data in the meetings and interviews are evaluated in terms of different dimensions by applying qualitative approach.

The rest of the paper is organized as follows: Section 2 includes literature survey about the software project failures, Section 3 presents a detailed real case study that is concluded by a failure and in the last section we discuss the reasons for failure in the case study.

\section{LITERATURE SURVEY}

There are many studies that employ software project failures in the last two decades. The researchers mostly focused on reasons for failure at different stages, project types, durations, technology, management and organizational failures. The researches in this subject were primarily conducted by qualitative research methods because of the nature of the problem domain in that one could not measure directly the effect of any factor in terms of cost, time and contribution to failure. There is also number of surveys about failure statistics of software projects in many ways.

Holland and Light (1999) discuss critical success factors for ERP implementation as in figure. Here critical success factors might be considered in two categories: long term factors as strategic and short term factors as tactical.

One of the most familiar series of surveys about software projects is conducted by Standish Group International. According to reports published by this research company in Standish Group (1994, 1996, 2004 and 2006), approximately 20 percent of software projects are cancelled before they completed and half of the projects' cost almost doubled their estimates. According to these reports overall success rates (i.e., meeting the budget, delivery, and meeting the business needs) of the projects are around 20 percent. IT project management, despite the fact that it deals with "modern" technologies, is embarrassingly immature in the mastery of risks. We see similar recriminating data year after year reminding us that about 20 percent of IT projects are canceled before completion and less than a third are finished on time and within budget with expected functionality.

Software development is approaching its 50 years as a profession. During this time there have been numerous success stories as well as many broadly publicized failures. These publicized failures are either associated with safety 
problems or substantial cost overruns and schedule delays. There are many more examples of these projects in the literature. Authors describe these projects as runaway and death-march projects (Glass, 1998).

Lindberg (1999) investigates the reason of high failure rates of $84 \%$ of software developers whereas researchers determined that software developer has much higher achievement needs than the general population. In his research, he provided an in-depth look at a project failure through the perspective of the software developers that worked on a software development project failure.

Jones' (2004) CrossTalk analyzes about 250 large software projects at or above 10,000 function points in size that were examined by the author's company between 1995 and 2004. Findings showed that when comparing large projects that successfully achieved their cost and schedule estimates against those that ran late, were over budget, or were cancelled without completion, six common problems were observed: poor project planning, poor cost estimating, poor measurements, poor milestone tracking, poor change control, and poor quality control (Jones, 2004).

Kappelman (2006) studied about early warnings of failure in software projects by conveying 53 symptoms that could be used as early detection. These symptoms can be grouped as people, process and product based symptoms.

The major factors that contribute to the success or failure of software systems fall into seven categories as management, customer and users, requirements, estimation and scheduling, the project manager, the software development process and development personnel (Procaciono et al., 2002).

One of the software companies in Turkey stated that the key point about getting failure in business software projects is around the defects in developing business model (Aksoy, 2007).

According to APICS, the important issues in software project managements are fitness to organizational structure, applicability and cost estimations before implementation step. In this manner cost dimension can be explained in terms of hardware, database, operating system, training, consultancy and others (APICS, 1999). 
Figure 1: A Critical Success Factors Model for ERP System Implementation

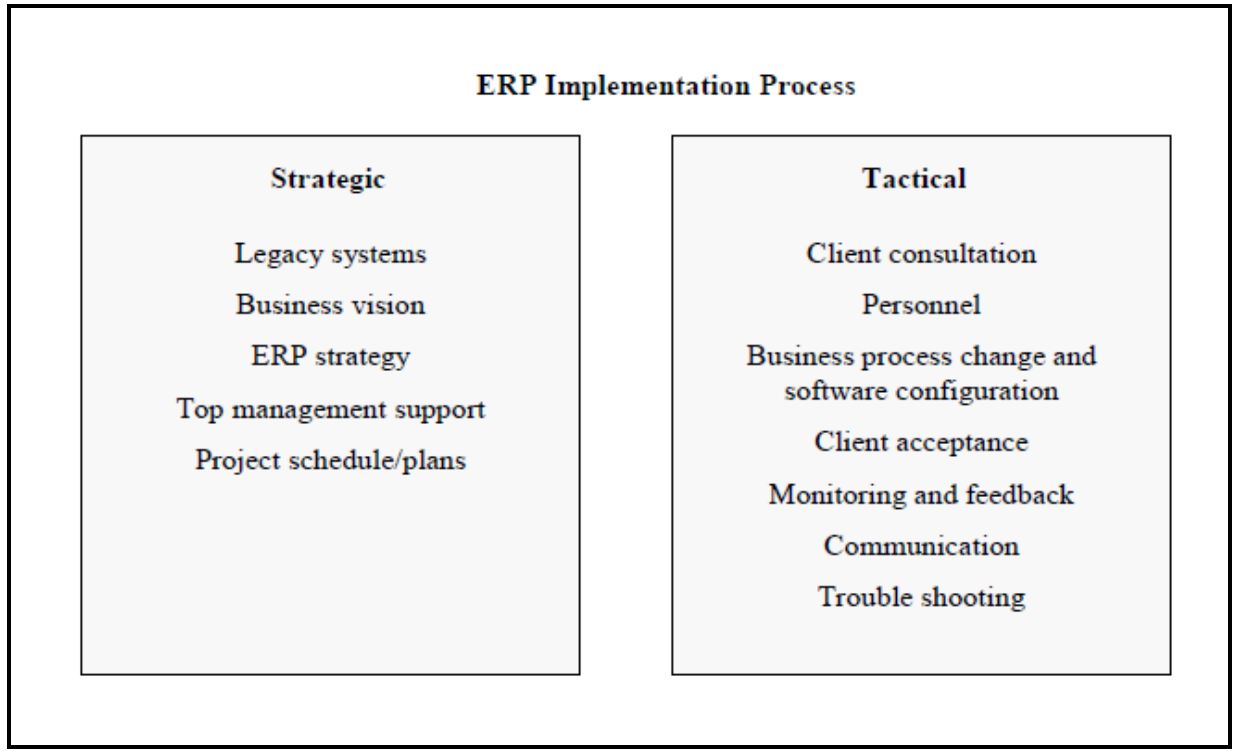

Source: Holland and Light (1999)

\section{CASE STUDY: A FAILURE STORY OF INTEGRATING BUSINESS SOFTWARE}

Almost in all countries there are plenty of software companies that are extensively focused on providing business solutions like basic accounting and financial operations, human resources, production, inventory, purchasing and sales operations. In the most of the business cases, software companies create customized solutions as mixture of existing software and company specific added ones. During the delivering of solution by starting the agreement on scope of the project, project time, cost and working conditions up to physically adapting and implementation, there are lots of difficulties with the project's application phases.

The case study here presents an ordinary mid-sized company implementation failure of three different software companies that is highly possible for similar business cases in the future.

\subsection{Customer Company Description}

The Customer Company (OzInc) is a leading company established in 1992 in Izmir and it produces, sells, purchases to/from other countries and it operates in a 10 thousand square meter closed area. There are two different business software installed and both of them are already currently in use. Organizational hierarchy has a flat structure consisting of a company GM, department chiefs 
and bottom level workers. General manager (GM) is responsible for every main operations inside the company such as daily production, sales, purchases, financial-accounting operations and information systems.

\subsection{Starting Project: Sales Analysis}

The phone rang and Vice GM called the Project Manager of Software Company (NTX) in 25 November 2008 and said that they sold their software product with some customizations and they should install firstly their software called as "basic set" while entering the new year within 3 weeks. Basic set involves basic functions of the business requirements such as billing, managing inventory operations, financial operations, and accounting operations.

SC sales representatives had promised that the full implementation cost with Customer Relationship Management (CRM) was around 30000 dollars and it would be payment for once. It is established in İmir and there would not be additional cost because of being here.

\subsubsection{Rough Cut Analysis}

As a second step of implementation, they should build a CRM for Ozlnc because there is no such a software module in their current software product spectrum. Finally, the project would be finished by integrating current production planning facilities with their relevant and existing software module after little modifications. In this time period the software provider company just feels the effect of the 2008 crisis that spreads quickly over the world and their software sales were going to decline sharply as $20-30 \%$ within $2-3$ months. Therefore this was an exciting sales agreement for them to increase their hope for the future. The owner of OzInc, who is also GM of the company, is very enthusiastic, hardworking person and willing to integrate this software to his company, even if it is necessary to work for this project at the weekends for a long time.

\subsection{Competitors}

Another important point of this project is that OzInc has some business software of other leading software companies in the market that is to be removed upon installing their software. In other words our software company will gain a prestige since their business software preferred to installed ones. Ozlnc uses two different companies' software for different purposes. One is for basic accounting operations and the other one is for managing production activities. It has been caused the duplicate entries for some of the transactional data that was related to accounting, production and sales activities since 2006. In fact the software used for production is capable of the accounting operations and most of the accounting plan is defined in it but nobody knows why the first software is preferred redundantly. 


\subsubsection{History of Business Software in the Company: Past Success/Failure Histories}

PX: Company of First Installed Software: Company is established in İstanbul. There is currently installed software in OzInc that operates basic accounting transactions but full functioning of accounting is achieved by co-working of AX and PX. If NTX is installed once, there will be no need for the others for accounting. Recently PX released a new ERP software included CRM and it is worth evaluating. $\mathrm{PX}$ is the first software installed in a company and customer manager talked to $\mathrm{PX}$ for ERP integration firstly but cost of the product was very high . Therefore second software is selected for ERP.

AX: Company of Second Software Installed: Company is established in İstanbul. It has robust and very flexible infrastructure with CRM module. It doesn't require great effort to adapt it, but its annual cost is as much as 30000 dollars. There is still ongoing interview with sales representatives. Location based constraints between İzmir and İstanbul might cause adaptation and other developments.

Leading analyst of $A X$ was very qualified and she could always understand what the company manager wanted and OzInc manager was very satisfied with the work she does. He always looks for such a consultant in other software projects and makes comparison between current consultants and AX's.

AX's consultant team was working at very high daily costs in İmir and implementation cost was about 400 thousand dollars. If the company manager decides to work with AX, he will suffer daily adapting costs and will have to meet the additional annual cost of 30000 dollars for licensing and upgrading. It is the most important disadvantages of AX. It seems that it is one of the most important points for selecting NTX.

\subsection{Initial Stage of Analysis}

As a first step of defining business requirements project managers went to OzInc with their project consultant in the first week of the February. It was weekend and OzInc's manager invited the entire employee to the starting meeting. In the first meeting they told us their general structure of working, organization and business processes. We used to prepare draft plan in our first meeting but in this case the meeting was progressing toward business analysis. For the first day consultant and project manager were trying to understand the business requirements and we considered how these processes could be implemented via our business software based on our first impression. OzInc manager thought that the software company would install their software within two or three days and OzInc could start operating upon installation. We expressed that it was impossible to implement within that time frame and it could take at least 3-4 months because adapting the software by means of leaving the legacy system has some affordable steps. Eventually, OzInc's GM 
was convinced and satisfied with these reasonable explanations. As a project manager and consultant we began to get worried about progress of the project in the near future and our first group of questions was raised upon this situation:

- Why did OzInc decide to left current business software that is used for operations management?

- Why did the company GM select our company?

- How could we implement some of the current processes that were achieved in an opposite way to us?

We were finding some answers to our questions but it was time to pay for the first part of the contracted cost. OzInc's GM said that they could not pay anything without demonstrating the model of inventory module. This situation was a sign for the weak contract and the lack of reliability between software and Ozlnc. Therefore we were going to focus on inventory part of the software to get some payment. We believed that we could adapt our existing inventory model easily to replace the legacy system by means of parametric arrangements without significant structural changes. That is why our inventory module named as flexible structured module.

\subsubsection{Determining Software Needs of the Company}

However, we requested our software team to develop some additional attributes for Ozlnc within the flexible structuring inventory module. Since this is a star project in this time period against our competitors, our GM promised to support all the required additional software changes and improvements by allocating software developers without considering cost-benefit ratio. We were conscious of that the more we requested additional changes the more we would steal time for regular software updates. On the other hand our chance to success in this project, get payment and integrate more robust software would decrease unless these revisions were made. Moreover, Ozlnc manager wanted to see a demonstration of the developed model in the working environment in a short time and it took significant time to express the impossibility of developing software in such a way.

\subsubsection{Understanding Business Requirements: Difficulties in Understanding Phase}

When we understood about disagreeing with Ozlnc manager on selecting flexible structuring as an inventory management model, our project consultant had to go urgently to abroad for a month. It was the first radical change in that it would put the project team into difficulty. By this time another consultant inside our company started to work with us. This person was implementer for small sized projects and he is currently at self development stage. OzInc was not affected by this radical change with their work. 
The second important meeting was on evaluating the steps achieved. We discussed about customer company's inventory structure. Our aim was to convince the company manager for replacing the flexible structuring model with the item-by-item inventory management since we began to consider that flexible structuring model was hard to adapt for the working structure of the company. The main reason for early prefering of flexible structuring model was that the existing legacy software used to similar system to this model and was managing only four main item types. These four types were maintained on the basis of size and vendors' attributes. It means that the part code involved material attributes (length, width and thickness) and vendor information as a set of numbers. In this meeting OzInc manager stated that it was difficult to create the entire materials if the project manager decided to implement new inventory system and he explained why they prefer using second business software for the inventory management. Finally we promised that we would develop a hybrid model that involves attributes of both legacy system and our product features by relying on our software team. OzInc's manager wanted to see the new promised model as soon as possible. We started to develop this special promised software with purchasing processes as well as inventory operations. Entire user interfaces would be renewed as special to OzInc.

With our decisions we would assign less amount of work to the software developer team and we would develop the user screens of the part code creating function of the inventory module. We would develop screens like legacy system but we could maintain the parts in our way without great changes in program code by means of creating relation's legacy system likely screens and our traditional system. After introducing these improvements in the new model, the company GM seemed to be satisfied with these developments but emphasized on their priorities about CRM and requested to focus on it.

Three weeks ago we introduced a CRM specialist to company GM and the specialist presented the basic information about CRM and suggested to begin with the basic operations' design. In that meeting, company GM has decided to begin with improvements in CRM. We found suitable to work with our new project leader for the CRM because of it would require different aspects rather than inventory management.

\subsubsection{NTX and OzInc's Perspective}

We created user interfaces with the CRM specialist within 6-7 business days. Then project consultant started developments for the main product groups. These developments were only achieved for animating the events in company GM's mind and establish trust. We made first presentation to show improvements in CRM and we showed all the user screens as the company GM expected and he satisfied with these screens but he requested to be able to enter data to CRM system in a spreadsheet format in a real working environment. 
Last developments and impressions were boring because we would back to basic developments stages again otherwise it could not be possible without achieving the basic implementations. Then we repeated that our software is built for general commercial purpose and we only could adapt our software to manage company's business process with small changes and could not create new software for them.

\subsection{Looking for Remedies to Get Rid of Misunderstanding: Hiring a Consultant as a Bridge Between NTX and OzInc}

In the CRM meeting we could not agree with OzInc's GM on CRM objects. It was meaningless to keep records about the customer like his wife's birthday, school grades, gender and ages of children. We blew up at GM against his unnecessary needs and our specialist told him that the most of his needs about CRM were meaningless and could involve some harmful effect since the violation of privacy. As a result, we quarreled over CRM and we suggested that a CRM consultant and process consultant was to be hired for Ozlnc. We finished this meeting after promising to find two consultants for structuring their CRM module.

We showed the inventory, purchasing and process model one week later. Although the models in the design stage, we built user screens that worked properly in terms of calculations and functionality. The model presentations included creating parts, defining the part attributes, inventory data entries, purchasing order entries, freight bill entries and purchase invoice.

\subsubsection{NTX has still trouble: Payment problems and Its Chain Effect to Management}

OzInc's GM's attitudes were taking attention of our sales department and our vice general managers. He told us they would not pay anything as long as having no satisfaction with inventory module through early meetings. He was keeping on his pessimistic attitudes against lots of the significant improvements and we were experiencing disappointment entirely.

We went to OzInc with the new CRM consultant as promised. The CRM consultant has been installing most of the modules of our software for the number of consulted company for many years as well as CRM consultancy. The CRM consultant was an industrial engineer, led many successful business projects and had her own consultancy firm. Consultant would play a bridge role between OzInc and us as understanding, refining, rationalizing the OzInc manager needs.

We focused on building CRM module and priority of adapting inventory management module was lowered. Our aim was to build CRM module as soon as possible. Firstly we would gain the respect of Ozlnc again by increasing sales potential with our software. To do this, CRM consultant desired few days 
for working and understanding OzInc and then consultant presented a CRM demonstration that impressed OzInc's GM. In our opinions consultant was best person for a bridge between two companies and he could build quickly an applicable model. Last thing was an agreement between CRM consultant and OzInc on consultancy cost, time and other working conditions.

\subsection{Dissatisfaction with the Progress of the Project}

When we went to OzInc with our vice general manager, OzInc manager said that he dissatisfied with the current situation and developments built so far. $\mathrm{He}$ complained us about we insisted on prioritizing inventory management and consumed much more time instead of building CRM module but CRM consultant could develop a fast and successful CRM model in two days. Moreover he criticized that why we could achieve such a model in a very long time. Moreover, he was undecided on hiring the CRM consultant because of extra higher cost. Eventually, OzInc manager said he wanted to review the CRM module of other software packages that were currently installed on and consider making developments on one of the software as an alternative. As a result he would make a decision as continuing with us or leaving us and continuing with others after evaluating the alternatives within one month. Our vice manager stated that one month is too long to make a decision and we could continue to work on the project within this time interval, but he refused.

As a project team we have to take the consequences of this dissatisfaction after the meeting. We were investigated about why we could not present a CRM demonstration like CRM consultant did. Our answer was to speed up the project and focusing on "basic set" which was a necessity for the rest of the project success and we sad that CRM was planned as a another major stage after adapting the basic set and inventory management module.

\subsubsection{The Great Misunderstanding}

We passed three weeks without getting any feedback from Ozlnc. Then we visited the company with our instructors for a planned research to get some data, project manager told us that what they understood from "basic set" was different from what we understood from it.

\subsubsection{Start with "Basic Set"}

We call the essential parts like vendors, customers, inventory, invoices and purchasing in our software as "the basic set" and we promised and prioritized to implement "the basic set" firstly. On the other hand OzInc's GM had completely perceived different thing in that the entire software included all the modules (i.e., inventory, CRM, vendors and etc.) will be "basically" installed at once as a "basic set" of implementation and then required adaptations would develop via small changes in the long run. There were a great gap in our standpoints and unfortunately we understood it after 4 months. 


\subsection{Freezing Project for Evaluating the Present Situation}

We didn't have any information for two weeks from the CRM studies of the consultant. When the project manager talked to CRM consultant, he said that OzInc's GM did not want to answer the call requests and provide him with an excuse of lots of works and could not allocate enough time for studying the project. Finally project manager called OzInc manager and manager said he wanted to have a talk with our vice general manager.

\subsection{Different Viewpoints about Basic Set of OzInc and NTX}

Moreover, another difference with our point of view was about feeding method of CRM system with data. We would provide the basic customer fixed data for the system via spreadsheet since end users could prepare data to initialize the system for once. On the other hand, they comprehend that they would use this spreadsheet in every time as entering data to system. At this point our main fault was to neglect the customer background and consequently confusing of terms and events, lack of informing the customer about the integration steps of our software with company business processes. We supposed that the customer contact person could understand what we told them technically, but it did not. Shortly, we had lack of empathy with OzInc representative.

Another important mistake was extending through the initial step of project: initial contracting and agreement on working conditions. There was a significant lack of communication between our sales department and of course their verbal promises and project group. They had not forwarded the priority information of the customer and project strategy to our group.

\subsection{Feelings of OzInc After 8 Months}

OzInc said that they told us they did not know about CRM too much. According to OzInc manager, if OzInc were them, OzInc would hire a CRM specialist definitely. The consultant came to OzInc and gave basic information. He advised that it was necessary to complete "the basic set" and CRM can be built up simultaneously.

Changing consultants as many times causes to tell everything again and again is so boring and time consuming process and it is not a professional approach. That is why we give up interviewing with the last consultant.

OzInc believes that they were misdirected about reporting structure and custom tailored reports in terms of types, costs and number of free custom designed reports.

OzInc manager feels himself as misled and deceived and he blames himself due to the fact that he should have been more conscious as a customer and audited the progress, should not have believed the verbal promises by 
salesperson of software company. He expected that the project should be finished as 70 percent so far.

OzInc manager impressions are listed below:

- Knowledge and experience of CRM specialist of NTX has at beginner level as compared to the others,

- There seems to have an organizational and communication based problem about informing the higher level of hierarchy about the real situation in the project,

- Dissatisfaction with the data conversion (i.e., utilizing spreadsheet software)

- OzInc manager does not evaluate the progress up to here as a great work done by the software company, according to OzInc, it is so simple that an ordinary spreadsheet user can build such a model himself.

- There is a lack of contracting that captures all the promises as a written statement even if there are some meeting reports sent via e-mail but company manager occasionally read his e-mails.

\subsection{Feelings of NTX's Project Manager}

NTX project leader confesses that this was their first project experience in this kind in that they were used to working with information technology department specialist and/or information system consultants, but this was different in terms of working manner.

\subsection{Looking for Other Alternatives}

Finally we concluded to evaluate the CRM alternatives with OzInc and instructors. In this last meeting each part of the project could say everything about progress easily since nothing remained to lose by this point.

\section{CONCLUSIONS}

We present a business case in this study and investigate the differences in understanding the customer and source of differences that cause the project failure. It can be generalized for other project implementations in similar situations.

The meeting notes and interviews show that the most of the factors affect the software development process with different importance level as starting from managerial effect to point of view and the project management style of the software developer in analysis and design. 
Understanding the customer is the most crucial step in that it is early step of entire development process and as in our case study showed that both side of the project should have a good communication.

Both sides of the implementation project should promise what make them really be able to do and offer within the working constraints such as project time, cost, technology and functional abilities of the final product.

It seems that there is a mistake on software development life cycle method: evolutionary or spiral model would be preferred rather than waterfall model because of keeping the priorities of OzInc.

It is necessary to employ a consultant between NTX and OzInc continuously. He should play an interface role as converting needs to requirements and preserving boundaries of the project.

There should be an information technology department within the company that is responsible for maintaining software projects, basic hardware and networking operations. It makes it easier to communicate with the software companies technically.

\section{REFERENCES}

Aksoy, E. (2007). "ERP Sistemlerinde Esneklik", http://www.ias.com.tr/enterprise/articles/20070402-erp-flexibility.html, Nisan 2007, Access Date:June 2009.

APICS (1999). www.apics.org/magazine/June 99/ERPTravis, Access Date:June 2009.

Holland C. P. and Light B. (1999). "A Critical Success Factors Model For Enterprise Resource Planning Implementation", Proceedings of the 7th European Conference on Information, available at: christopherholland.co.uk.

Jones, C. (2004). "Software Project Management Practices: Failure Versus Success", CrossTalk: The Journal of Defense Software Engineering, 5-9. available at: www.stsc.hill.af.mil

Kappelman A. L., Robert M., and Lixuan Z. (2006). "Early Warning Signs of IT Project Failure: The Dominant Dozen", Information Systems Management, 23:4, 31-36

Linberg R. K. (1999). "Software developer perceptions about software project failure: a case study", The Journal of Systems and Software, 49, 177-192.

Lyytinen, K. \& Robey D. (1999). "Learning failure in information systems development”, Information Systems Journal, 9, 85-101. 
Procaccino. D. J, June M. V., Scott P. O. and Marvin E. D. (2002). "Case study: factors for early prediction of software development success", Information and Software Technology, 44, 53-62.

Standish Group. (1994). "CHAOS Report". West Yarmouth, MA: The Standish Group International, Inc.

Standish Group. (1996). "CHAOS Report". West Yarmouth, MA: The Standish Group International, Inc.

Standish Group. (2004). "CHAOS Report". West Yarmouth, MA: The Standish Group International, Inc.

Standish Group. (2006). "CHAOS Report". West Yarmouth, MA: The Standish Group International, Inc.

Welke, R.W, (1994). "The shifting software development, paradigm". Data Base, 25 (4), 9-16. 